\title{
Tissue Inhibitor of Metalloproteinases-1 (TIMP-1) Is Differentially Induced in Neurons and Astrocytes after Seizures: Evidence for Developmental, Immediate Early Gene, and Lesion Response
}

\author{
Santiago Rivera, Evelyne Tremblay, Serge Timsit, Oriol Canals, Yezekiel Ben-Ari, and Michel Khrestchatisky \\ Université René Descartes, Paris V, Institut National de la Santé et de la Recherche Médicale Unité-29, \\ 75014 Paris, France
}

\begin{abstract}
We investigated in vivo the expression of the tissue inhibitor of metalloproteinases-1 (TIMP-1) in the rat CNS after kainate (KA)induced excitotoxic seizures. In situ hybridization revealed that TIMP-1 mRNA is induced rapidly and massively in most regions of the adult forebrain after KA treatment. Neuronal activity seems to be necessary but not sufficient to trigger TIMP-1 induction, because it is not observed in seizing 10-d-old pups, unlike what is observed in 21- and 35-d-old animals after seizures. The rapid induction of TIMP-1 is not prevented by the inhibitor of protein synthesis cycloheximide, suggesting that, after seizures, TIMP-1 is induced in neurons as an immediate early gene (IEG). The initial neuronal upregulation is followed by enhanced expression in astrocytes, as assessed by double-labeling experiments. In the hip-
\end{abstract}

pocampus rapid increases in mRNA are followed by relatively delayed ( $8 \mathrm{hr}$ after KA) increases in TIMP-1 immunoreactivity in the perisomatic and dendro-axonic areas, suggesting secretion of the protein. At $3 \mathrm{~d}$ after KA treatment, strong immunoreactivity is found in astrocytes and in the cell bodies and dendro-axonic projections of resistant neurons such as the dentate granule cells. Taken together, the results suggest that TIMP-1 may be instrumental for neurons and astrocytes in coupling early cellular events triggered by seizures with the regulation of long-lasting changes involved in tissue reorganization and/or neuroprotection.

Key words: TIMP-1; protease inhibitor; brain seizures; neuronal death; immediate early gene; astrocytes; extracellular matrix; tissue remodeling
Tissue inhibitor of metalloproteinases-1 (TIMP-1) is a $28.5 \mathrm{kDa}$ secreted glycoprotein (Murphy et al., 1977; Cawston et al., 1981) that shares 40 and $28 \%$ amino acid sequence homology with its family partners TIMP-2 (Stetler-Stevenson et al., 1989) and TIMP-3 (Apte et al., 1994; Leco et al., 1994), respectively. Although considered a multifunctional molecule that possesses growth-promoting properties (Docherty et al., 1985; Gasson et al., 1985) and mitogenic activity (Bertaux et al., 1991; Hayakawa et al., 1992) in a variety of cultured cells, TIMP-1 is recognized mostly as an inhibitor of matrix metalloproteinases (MMPs) (Cawston et al., 1981). MMPs constitute a family of zinc-binding and $\mathrm{Ca}^{2+}$-dependent endopeptidases, including gelatinases, collagenases, and stromelysins (Emonard and Grimaud, 1990). The excessive cleavage of the extracellular matrix (ECM) associated with an imbalance of the MMPs/TIMPs ratio has been correlated with the invasive potential of brain tumor cells (Khokha et al., 1989; Nakagawa et al., 1994; Mohanam et al., 1995) and with the histopathogenesis of inflammatory-related diseases like rheumatoid arthritis or multiple sclerosis, as reviewed by Dayer and Burger (1994) and by Hodgson (1995).

In non-neural cells the expression of MMPs and TIMP-1 is modulated by extracellular factors, including cytokines and

\footnotetext{
Received Nov. 20, 1996; revised Feb. 25, 1997; accepted March 25, 1997.

This research was supported by funding from the Institut National de la Santé et de la Recherche Médicale. S.R. was granted a fellowship from the government of Catalonia and a Biomed I fellowship from the European Union. The c-fos antibody was a generous gift from Dr. R. Wehrle. We thank Elena Prats for technical assistance and Dr. M. Esclapez and J. Levav for critical reading of this manuscript. We dedicate this article to Dr. Yoav Citri, in memoriam.

Correspondence should be addressed to Dr. Santiago Rivera, Institut National de la Santé et de la Recherche Médicale U-29, Hôpital de Port Royal, 123 Boulevard Port Royal, 75014 Paris, France.

Copyright (C) 1997 Society for Neuroscience 0270-6474/97/174223-13\$05.00/0
}

growth factors like TNF- $\alpha$ (Chua and Chua, 1990; So et al., 1992), IL-1 $\beta$ (Shingu et al., 1993), bFGF, EGF, and TGF $\beta$ (Edwards et al., 1987) and by phorbol esters (Murphy et al., 1985). In contrast, very little is known about the regulation of TIMP-1 expression in the CNS. Nedivi et al. (1993) first isolated TIMP-1 as a candidate plasticity gene in the dentate gyrus of kainate (KA)-treated rats and demonstrated, by using Northern blot approaches, that its expression is modulated in this region by stimuli producing longterm potentiation and during postnatal development. These observations are in keeping with the hypothesis that controlled proteolysis is crucial in the development and plasticity of the CNS (Lynch and Baudry, 1984; Monard, 1988; Frey et al., 1996), whereas excessive proteolysis contributes to various neuropathologies (Siman et al., 1989; Lee et al., 1991; Rosenberg et al., 1992). In particular, brain seizures and associated pathology recently have been linked with alterations of serine protease expression (Qian et al., 1993; Chen et al., 1995; Tsirka et al., 1995), mutations in an endogenous cysteine protease inhibitor (Pennacchio et al., 1996), and, most interestingly, with the induction of stromelysin-1 (Reeben et al., 1996), a metalloproteinases that is inhibited by TIMP-1 (Murphy et al., 1991). Taken together, these data strongly suggest that proteases are involved in seizure-associated pathology and that their inhibitors, including TIMP-1, may be instrumental in regulating their deleterious effects. To evaluate this hypothesis, we find it is important first to establish the distribution and regulation of TIMP-1 in the seizing brain.

As an extension of the findings of Nedivi et al. (1993), we report here that KA-mediated excitotoxic seizures induce TIMP-1 expression in a time-, region-, cell-, and age-dependent manner and that the initial induction in neurons is independent of novel protein synthesis. In addition, we discuss the differential and 
sustained expression of TIMP-1 in neurons and astrocytes in relation with pathology.

\section{MATERIALS AND METHODS}

Animals and treatments. Experiments involving animals were approved by the French Ethical Science Committee (Statement No. 04223). They were performed with male Wistar rats at various postnatal ages (P). Rat had access to food and water ad libitum and were housed under a $12 \mathrm{hr}$ light-dark cycle at $22-24^{\circ} \mathrm{C}$. All drugs were injected intraperitoneally $(0.5$ $\mathrm{ml} / 100 \mathrm{gm}$ ). Seizures were induced, as previously described (Tremblay et al., 1984), by KA (Sigma, St. Louis, MO) dissolved in $0.9 \%$ saline and given at varying doses, depending on the postnatal age: $1-2 \mathrm{mg} / \mathrm{kg}$ at P10, $6-7 \mathrm{mg} / \mathrm{kg}$ at P21, and $9-10 \mathrm{mg} / \mathrm{kg}$ at P35-P60. After KA injection each animal was placed in a Plexiglas cylinder for behavioral observation. The animals that did not show a stereotyped seizure behavior were not included in the study. Control animals were injected with the same volume of $0.9 \%$ saline.

After various delays after KA injections (from 50 min to $14 \mathrm{~d}$ ), 65 adult animals (P60) were anesthetized with pentobarbital and decapitated; their brains were removed rapidly onto a cold plate, dipped for $1 \mathrm{~min}$ in cold isopentane $\left(-50^{\circ} \mathrm{C}\right)$, and then stored at $-80^{\circ} \mathrm{C}$ until they were sliced into cryostat sections $15 \mu \mathrm{m}$ thick, mounted onto gelatinized slides, and kept at $-70^{\circ} \mathrm{C}$ until used for in situ hybridization, immunohistochemistry, or histology. Three KA-treated animals and their respective saline controls received, in addition, repeated injections of the anticonvulsive drug diazepam ( $25 \mathrm{mg} / \mathrm{kg}$, Hoffmann-La Roche, Basel, Switzerland) and were killed 90 min later.

A separate group of 12 adult rats was used to study the effects of the protein synthesis inhibitor cycloheximide on the KA-mediated TIMP-1 mRNA induction. Animals were injected with (1) KA (10 mg/ $\mathrm{kg})$ alone; (2) $2 \mathrm{mg} / \mathrm{kg}$ cycloheximide twice, $1 \mathrm{hr}$ before and $1 \mathrm{hr}$ after KA injection; (3) cycloheximide plus saline twice, as in (2); and (4) saline control. In this paradigm animals were killed $2 \mathrm{hr}$ after KA or saline injections.

For studies addressing the developmental regulation of TIMP-1 mRNA expression by seizures, we treated 18 rats of P10, P21, and P35 with either saline or KA. Sixteen hours later they were killed, and tissue was processed as indicated above.

For TIMP-1 immunohistochemistry and double-labeling procedures combining in situ hybridization and immunohistochemistry, 18 adult rats were treated with KA $(10 \mathrm{mg} / \mathrm{kg})$ and 6 with saline and intracardially perfused with $0.9 \%$ saline, followed by $4 \%$ paraformaldehyde in $0.1 \mathrm{M}$ phosphate buffer (PPB) at various times: 1.5, 4, 8, 16, and $72 \mathrm{hr}$ and $14 \mathrm{~d}$ after treatment. Brains were removed rapidly onto a cold plate, post-fixed for $24 \mathrm{hr}$ in PPB at $4^{\circ} \mathrm{C}$, cryoprotected for $24 \mathrm{hr}$ in PPB containing $20 \%$ sucrose, and sectioned ( $24 \mu \mathrm{m}$ thickness) in the coronal plane with a freezing microtome. Tissue sections were collected into PPB and stored at $4^{\circ} \mathrm{C}$ for at least $3 \mathrm{~d}$ before further processing.

In all experiments a minimum of three animals per age and treatment were used for statistical analysis with the nonparametric Kruskal-Wallis test, followed by the Mann-Whitney $U$ test, for comparison between pairs of groups.

In situ hybridization. In vitro transcription of ${ }^{35} \mathrm{~S}-\mathrm{UTP}$ labeled TIMP-1 riboprobes was performed from linearized pBluescript plasmids with a Promega (Madison, WI) in vitro transcription kit with T7 (Pharmacia, Uppsala, Sweden) and T3 (Boehringer Mannheim, Mannheim, Germany) RNA polymerases for sense and antisense probes, respectively. The plasmid (kindly provided by Dr. Yoav Citri, Weizmann Institute of Science, Israel) carried a $700 \mathrm{bp}$ rat cDNA containing part of the $5^{\prime}$ untranslated region and the entire coding region. This probe recognized only one band where size corresponds to the TIMP-1 mRNA on Northern blots with brain RNA (Nedivi et al., 1993). Because a 150 bp sequence of the TIMP-1 $3^{\prime}$ coding region is highly homologous to a sequence contained in murine $\beta$-interferon (Skup et al., 1982), control experiments were performed with a ${ }^{35} \mathrm{~S}-\mathrm{dATP}$-labeled oligonucleotide selected in a region of the rat TIMP-1 (5' 79-123 $\left.3^{\prime}\right)$ nonhomologous to $\beta$-interferon. The in situ hybridization results obtained with such an oligoprobe were identical to those obtained with the TIMP-1 riboprobe in both control and KA-treated animals.

Frozen sections were brought to room temperature and fixed in cold $4 \%$ paraformaldehyde in $0.1 \mathrm{M}$ phosphate buffer (PB) for $30 \mathrm{~min}$ and then rinsed in glycine-phosphate buffer, acetylated, rinsed, dehydrated, delipidated, and incubated with $1 \times 10^{6} \mathrm{cpm} / 100 \mu \mathrm{l}$ of antisense or sense riboprobes overnight at $50^{\circ} \mathrm{C}$. Tissue was rinsed twice for $30 \mathrm{~min}$ at $60^{\circ} \mathrm{C}$ in $4 \times \mathrm{SSC}$, treated with $20 \mu \mathrm{g} / \mathrm{ml}$ RNase A (Boehringer Mannheim), and finally washed in increasingly stringent conditions up to $0.1 \times \mathrm{SSC}$ at $60^{\circ} \mathrm{C}$ during $30 \mathrm{~min}$. All tissue was processed for both film (Biomax, Kodak, Rochester, NY) and emulsion autoradiography (NTB2, Kodak), with exposure times of 3-5 d and 3-4 weeks, respectively. After development of emulsion autoradiograms, the sections were counterstained with cresyl violet and mounted with Permount.

Densitometric analysis of mRNA levels on film autoradiograms was performed with the Samba/2005 image analysis system (TITN Alcatel, France). Multiple measures were obtained from at least four tissue sections per brain from each rat.

Immunohistochemistry. For TIMP-1 immunohistochemistry PPB fixed floating sections were rinsed in PBS. Endogenous peroxidase activity was inhibited with $0.1 \% \mathrm{H}_{2} \mathrm{O}_{2}$ (Sigma) for $20 \mathrm{~min}$. Tissue was preincubated for $30 \mathrm{~min}$ at room temperature in PBS plus 0.1\% Triton X-100 (Sigma), $0.2 \%$ gelatin (Bio-Rad, Munich, Germany), and 3\% normal goat serum (Vector Laboratories, Burlingame, CA) and then incubated at $4^{\circ} \mathrm{C}$ overnight in a solution containing a rabbit polyclonal anti-TIMP-1 (1:500, Chemicon, Temecula, CA) plus $0.1 \%$ Triton plus $0.2 \%$ gelatin plus $1 \%$ normal goat serum. This antibody recognizes the rat protein and does not cross-react with any other protein on Western blots. Tissue then was rinsed in PBS, incubated $1 \mathrm{hr}$ at room temperature with a biotinylated goat anti-rabbit antibody (1:400, Vector), rinsed in PBS, incubated for 90 $\mathrm{min}$ at room temperature in the avidin-biotin-peroxidase kit (ABC kit, Vector), developed in $0.05 \%$ diaminobenzidine (Sigma) plus $0.2 \%$ ammonium nickel (II) sulfate (Sigma) plus $0.1 \% \mathrm{H}_{2} \mathrm{O}_{2}$ in $0.05 \mathrm{M}$ Tris buffer, dehydrated, and mounted.

To verify an efficient inhibition of protein synthesis by cycloheximide, we tested whether KA-induced expression of Fos protein was blocked by cycloheximide administered before and after KA injections. Adjacent brain sections to those used in the in situ hybridization study for TIMP-1 mRNA expression were fixed for $20 \mathrm{~min}$ in cold PPB and processed as described above with slight modifications: the incubation solution contained $0.1 \mathrm{M}$ lysine instead of normal goat serum; the first antibody was a rabbit polyclonal anti-human Fos (PCO5, Oncogene Science, Uniondale, NY) diluted 1:1000 in PBS containing 0.1\% gelatin and 0.15\% Triton; streptavidine-biotin-peroxidase (1:400, Vector) was used instead of the ABC kit.

In all cases, sections incubated in the absence of the primary antibody were not immunoreactive.

Double-labeling procedures combining in situ hybridization and immunohistochemistry. To identify precisely the cell types expressing TIMP-1 mRNA, we combined in situ hybridization with a TIMP- $1{ }^{35}$ S-cRNA probe and immunohistochemistry, using either a neuronal (MAP-5 antibody) or an astrocytic (GFAP antibody) marker. Using microtome-cut floating sections, we performed in situ hybridization as indicated above, except for the dehydration and delipidation steps that were performed after the immunohistochemistry procedure. After the last wash in $0.1 \times \mathrm{SSC}$, tissue was rinsed three times for $10 \mathrm{~min}$ in PBS, $\mathrm{pH}$ 7.4, preincubated for $1 \mathrm{hr}$ in a PBS solution containing $2 \%$ gelatin, $3 \%$ normal goat serum and $0.1 \%$ Triton $\mathrm{X}-100$, followed by overnight incubation at $4^{\circ} \mathrm{C}$ with either rabbit polyclonal antiGFAP (1:300, Dako, High Wycombe, UK) or mouse monoclonal antiMAP-5 (1:2000, Sigma) in PBS containing 2\% gelatin and 1\% normal goat serum. The next day, tissue was rinsed in PBS, incubated with a biotinylated goat anti-rabbit or goat anti-mouse antibody (1:400, Vector) for $1 \mathrm{hr}$, rinsed in PBS, incubated with the ABC kit (1:200) for $1 \mathrm{hr}$, rinsed, and developed with DAB (without nickel intensification). Sections were mounted, dehydrated, delipidated, and processed for emulsion autoradiography, as indicated above.

Histology. Cresyl violet was used to evaluate general histology and cell degeneration in cryostat sections adjacent to those used for in situ hybridization studies.

\section{RESULTS}

\section{Seizures in developing and adult rats}

The behavioral effects induced by systemic administration of KA varied with the postnatal age, as previously described (Ben-Ari et al., 1981; Tremblay et al., 1984). Thus, in P10 animals scratchinglike movements appeared after 20-25 min of KA injection, rapidly followed by tonicoclonic seizures. Scratching-like movements still were observed in P21 rats after KA, but not in P35-P60 animals receiving the glutamate analog. Moreover, in P21, P35, and P60 animals, KA injections induced "wet-dog shakes" 35-45 min after injection, followed 25-30 min later by typical limbic 
motor seizures (but no tonicoclonic seizures) and status epilepticus that could last for several hours. Cycloheximide treatment did not modify the behavioral manifestations of KA-induced seizures.

\section{TIMP-1 mRNA expression after KA-induced seizures in} adult rats

In control adult animals (Fig. $1 A$ ) mRNA expression appeared to be very low in most forebrain areas with the exception of the hippocampus, which exhibited above average hybridization levels. In contrast, parenteral injections of KA dramatically induced TIMP-1 mRNA in a time- and region-specific manner (Figs. 1, 2). No changes in basal TIMP-1 hybridization signal were detected before the manifestation of behavioral seizures (50 min after KA injection). However, as early as $90 \mathrm{~min}$ after KA injection (between 15 and $30 \mathrm{~min}$ after the onset of behavioral seizures), the expression of TIMP-1 mRNA increased strongly in the stratum granulosum of the hippocampus (Fig. $1 B$ ). Peak expression in this layer occurred between 4 and $8 \mathrm{hr}$ (Fig. 1C), as shown by tenfold increases measured by densitometric analysis of the film autoradiograms (Fig. 2). During the first $8 \mathrm{hr}$ statistically significant ( $p<$ 0.01 ) increases in mRNA levels, between two- and fourfold, also were detected in the strata pyramidale of regions CA1 and CA3, respectively. By $8 \mathrm{hr}$ post-KA injection (Fig. 1C,I), increased labeling no longer was restricted to the neuronal cell layers but also was distributed as scattered clusters of autoradiographic grains in all laminae. In addition, at this time point, hybridization also was highly elevated in amygdaloid nuclei, the entorhinal cortex, the primary olfactory cortex, and the hypothalamus and was increased slightly in superficial layers of the neocortex and in the paraventricular thalamic nuclei. In brains from animals killed at 16 (Fig. $1 D, J)$ and $24 \mathrm{hr}$ post-KA treatment, the hybridization signal was increased further in the strata radiatum, oriens lucidum, and lacunosum moleculare of the hippocampus proper and in the molecular layer and the hilus of the dentate gyrus, along with areas of the neocortex, the medial thalamic nuclei, and the hypothalamus. Hybridization signal remained highly elevated in the entorhinal and olfactory cortex. Densitometric analysis (Fig. 2) revealed that, by $24 \mathrm{hr}$ post-KA injection, TIMP-1 mRNA levels peaked in the strata pyramidale of regions CA1 (fourfold increase, $p<0.01$ ) and CA3 (sevenfold increase, $p<0.01$ ) while dropping to values six- to sevenfold $(p<0.01)$ of those of paired control animals in the dentate gyrus. At 48 and $72 \mathrm{hr}$ (Fig. 1E), labeling remained elevated in areas of degeneration such as the stratum pyramidale of the hippocampus $(p<0.5)$, the amygdaloid nuclei, and the superficial and deep layers of the entorhinal cortex, as compared with labeling in control animals. Thereafter, hybridization signal progressively declined across all brain regions, virtually reaching control levels by $14 \mathrm{~d}$ post-KA treatment (Fig. $1 G$ ). The KA-induced increase in TIMP-1 mRNA levels was blocked by systemic co-injections of the GABA/benzodiazepine receptor agonist diazepam (results not shown), which also blocked seizure activity, indicating that the induction of the mRNA expression was not attributable to a nonspecific effect of KA. Hybridizations with the cRNA sense probe gave no labeling in brain sections of saline- and KA-treated animals (Fig. $1 H$ ).

\section{Developmental regulation of TIMP-1 mRNA expression after KA-induced seizures}

To investigate whether neuronal activity was sufficient to induce TIMP-1 mRNA expression and whether it could be correlated with the developmentally linked neuronal vulnerability to KA, we treated animals 10,21 , and 35 d postnatal with convulsant doses of
KA. We then evaluated the expression of TIMP-1 mRNA $16 \mathrm{hr}$ later by in situ hybridization both in these animals and in their respective controls (Fig. 3). TIMP-1 mRNA was expressed poorly in the brains of control animals at all developmental stages studied. Maximum levels of TIMP-1 mRNA expression were found in the granule cell layers of the cerebellum and the main hippocampal neuronal layers of 10-d-old animals. The density of labeling was greater in the stratum pyramidale of region CA1 and in the stratum granulosum than in the stratum pyramidale of CA3. Hybridization signal in the pyramidal and granule cell layers of the hippocampus decreased throughout postnatal development and was lowest in P35 animals (Fig. 3E). In KA-treated animals TIMP-1 mRNA was not induced in response to generalized tonicoclonic seizures in 10-d-old rats (Fig. 3B). In contrast, by P21 (Fig. 3D) and P35 (Fig. 3F), increases of TIMP-1 mRNA levels in response to limbic seizures were $\sim$ five- to tenfold, as compared with age-paired controls in specific brain structures. Increases in P21 brains were confined to the hippocampus, the anterior septal, hypothalamic, and rhinencephalic areas of projection. In P35 animals, these increases extended to the entire cortical area, the caudate putamen, and the thalamic and hypothalamic nuclei. No changes in TIMP-1 mRNA expression were observed in the cerebellum or the midbrain after KA treatment.

\section{Effects of cycloheximide on KA-mediated induction of TIMP-1 mRNA}

The rapid induction of TIMP-1 mRNA expression after KAinduced seizures and its propagation in the limbic system was reminiscent of the pattern of expression of various immediate early genes (IEG). To establish whether the rapid seizuremediated induction of TIMP-1 mRNA was dependent on novel protein synthesis, we injected the protein synthesis inhibitor cycloheximide $1 \mathrm{hr}$ before and $1 \mathrm{hr}$ after KA or saline injections. As illustrated in Figure 4, cycloheximide treatment (Fig. 4B,D) did not alter the expression of TIMP-1 mRNA in the granule cell and pyramidal layers of control (Fig. $4 A$ ) and KA-treated animals (Fig. $4 C$ ). However, it blocked (Fig. $4 F$ ) the KA-mediated induction of Fos protein (Fig. $4 E$ ), indicating that inhibition of protein synthesis had been effective. No Fos immunostaining was detected in brains from saline- or saline/cycloheximide-injected animals (results not shown).

\section{Colocalization of TIMP-1 mRNA with neuronal and astroglial markers}

The distribution of TIMP-1 labeling after KA treatment suggested that mRNA expression predominantly increased in neurons up to $8 \mathrm{hr}$ after treatment and in both neurons and glial cells thereafter. For confirmation, KA-treated animals and their respective controls were killed at 1.5, 8, and $16 \mathrm{hr}$ after injections. Brain tissue sections were processed for simultaneous in situ hybridization autoradiography and immunohistochemistry with either MAP-5specific or GFAP-specific antibodies for neuronal and astroglial identification, respectively. At 1.5 and $8 \mathrm{hr}$ post-KA, the highest density of labeling overlapped MAP-5 stained areas of high neuronal body density. When they were observed at high magnification, it was obvious that dense clusters of silver grains associated primarily with MAP-5-positive dentate granule cells (Fig. 5A), piriform cortex (Fig. 5C) and amygdaloid neurons (data not shown), and less densely packed grains overlapped neurons in the hippocampal pyramidal cell layer, in the neocortex, in the thalamus, and in the hypothalamus (data not shown). Hippocampal interneurons appeared generally unlabeled, and GFAP-positive 

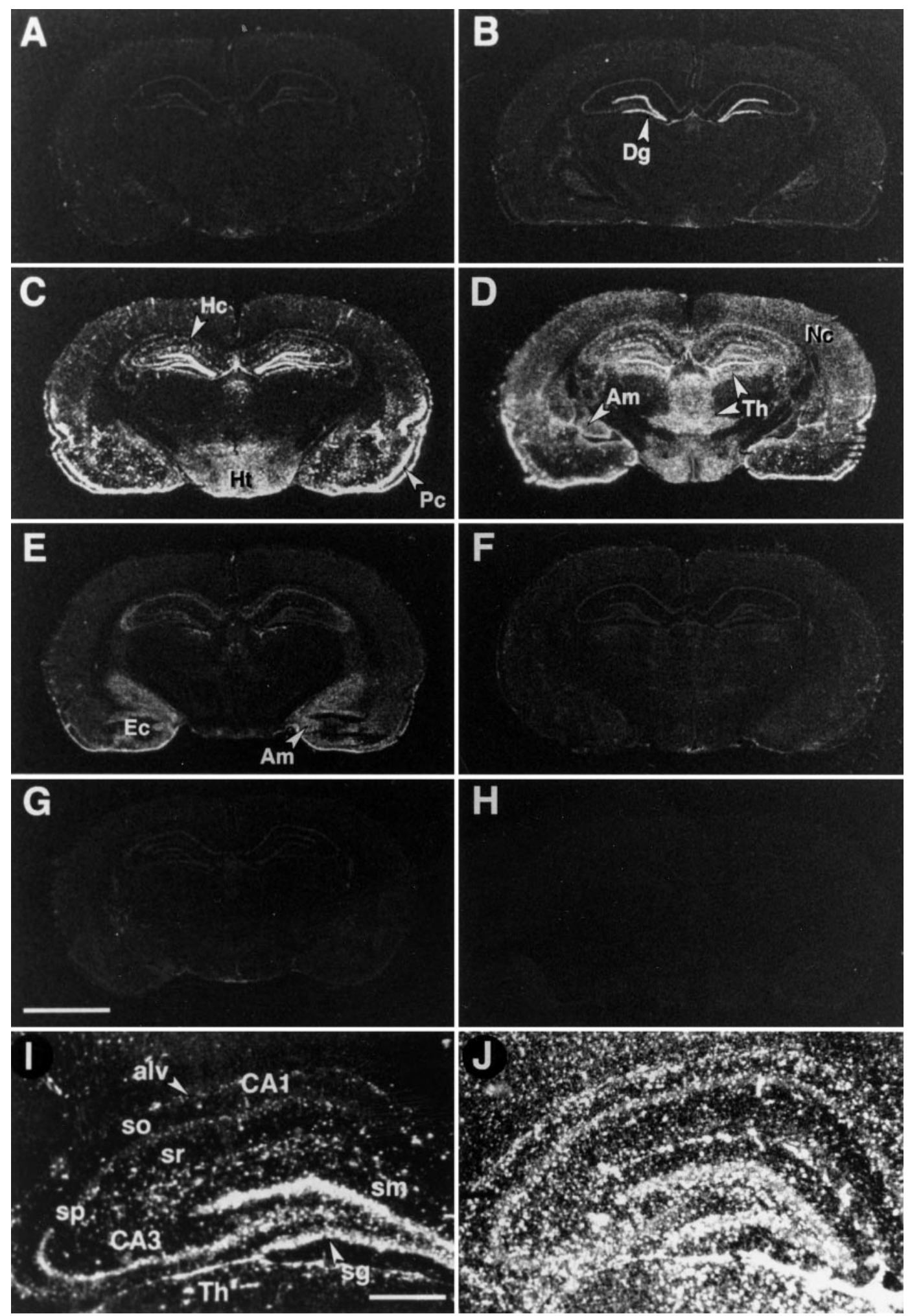

Figure 1. TIMP-1 mRNA is induced transiently in the adult rat brain after KA-induced seizures. Autoradiographs of coronal brain sections show in situ hybridization to an antisense ${ }^{35}$ S-labeled TIMP-1 cRNA probe in a control animal $(A)$ and at different times after KA injections: $1.5(B), 8(C), 16(D)$, and 72 $\mathrm{hr}(E)$ and $7(F)$ and $14 \mathrm{~d}(G) . H$ shows the absence of labeling with the sense probe. The hybridization signal first increases markedly in the granule cells of the dentate gyrus $(D g)$ at $1.5 \mathrm{hr}$ post-KA injection and progressively spreads to the entire hippocampus $(H c)$ and to other structures of the limbic system such as the hypothalamus $(H t)$, the piriform cortex $(P c)$, and the amygdaloid complex $(\mathrm{Am})$ and related structures such as the thalamus $(\mathrm{Th})$ and the neocortex $(\mathrm{Nc})$. By $72 \mathrm{hr}$ post-KA, elevated hybridization signal persists in the hippocampal $C A 1$ and $C A 3$ areas, in the amygdaloid nuclei, and in the entorhinal cortex $(E c)$. Scale bar, $3 \mathrm{~mm}$. I, J, Represented are dark-field emulsion photomicrographs of $\left({ }^{35} \mathrm{~S}\right)$-TIMP-1 cRNA hybridization in the hippocampus 8 and $16 \mathrm{hr}$ after KA treatment, respectively. At $8 \mathrm{hr}$, increases in hybridization signal are found mainly in the stratum pyramidale ( $s p$ ) of $C A 1$ and $C A 3$ and in the stratum granulosum ( $s g$ ) of the dentate gyrus. At $16 \mathrm{hr}$, note the large increase in hybridization outside these main neuronal cell body layers in the strata moleculare $(s m)$, radiatum ( $s r)$, oriens $(s o)$, and in the alveus $(a l v)$. Note as well the increase in medial and dorsal thalamic nuclei $(T h)$. Scale bar, $500 \mu \mathrm{m}$. 


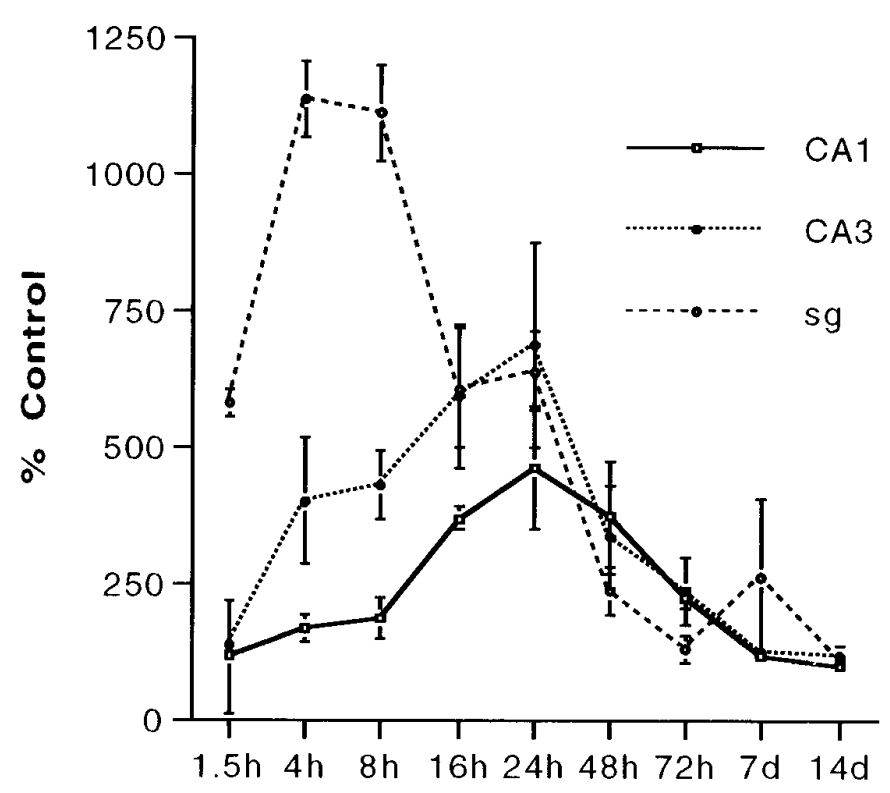

Time post-KA

Figure 2. Quantification of seizure-induced changes in the density of in situ hybridization to TIMP-1 mRNA in the hippocampal neuronal layers of adult rats at different hours $(h)$ or days $(d)$ after KA treatment. Values represent the mean \pm SEM of three to four rats per time point and are expressed as a percentage of density measures obtained from paired control rats. The nonparametric Kruskal-Wallis test, followed by the Mann-Whitney $U$ test, was used. The time course of TIMP-1 expression in all three areas, the pyramidal layers of $C A 1$ and $C A 3$ regions and the stratum granulosum $(\mathrm{sg})$ of the dentate gyrus, was significantly different from control values (Kruskal-Wallis test, $p<0.001$ ). See Results for statistically significant differences based on the Mann-Whitney $U$ test.

cells exhibiting astrocyte morphology displayed a low density of grain clustering (Fig. $5 B$ ). At 16 post-KA injection, the density of the autoradiographic grains was increased or reduced over MAP5-positive cells (Fig. 5E), depending on the neuronal population, and clearly increased over GFAP-stained cells (Fig. 5D,F) across all of the regions expressing TIMP-1 mRNA. Most GFAP-positive cells were labeled with TIMP-1 cRNA, and a particularly intense signal was observed in the non-neuronal cell body layers of the hippocampus and in the amygdala. Overall, radiolabeling was confined to neuronal and glial cell bodies, with some astrocytes showing hybridization signal in their immunostained processes only occasionally.

\section{TIMP-1 immunoreactivity in normal brain and after KA-induced seizures}

TIMP-1 immunostaining in adult brains was distributed broadly across cerebellar (data not shown) and forebrain regions. In all brain areas examined, the main locus of TIMP-1 immunoreactivity appeared to be the cell bodies and processes of cells morphologically identified as neurons. In most cases, the latter exhibited a clear perinuclear staining; occasionally, a few neurons appeared to be labeled in the nuclear compartment also. Light immunostaining also was observed in dendritic areas of different brain regions such as the stratum lucidum of region $\mathrm{CA} 3$ and the dentate molecular layer in the hippocampus (Fig. 6A). Within the neuronal hippocampal layers immunoreactivity decreased along the rostrocaudal axis of the brain. In the same coronal plane the intensity of staining ranked as follows: CA1 $>$ DG $>$ CA3 (Fig.
$6 A)$. Outside the hippocampus robust immunostaining was observed in neurons of the neocortex, the cingulate, and the piriform cortex, whereas it was lighter in thalamic and amygdaloid neurons (data not shown). Staining in areas enriched in white matter, like the corpus callosum, was close to background levels, and only at high magnification were we able to detect the presence of immunoreactive glial cells. The pia mater and the ependymal lining of the ventricles also were immunoreactive. No other signs of glial TIMP-1 immunoreactivity were detected in control brains.

Changes in TIMP-1 immunoreactivity after seizures seemed to be region- and cell type-specific across time. At $4 \mathrm{hr}$ after KA injections there was no evidence for changes in TIMP-1 immunoreactivity in the hippocampus (data not shown), as compared with saline-injected controls or in any other brain structure studied. By 8 (Fig. 6B) and 16 hr (data not shown) post-KA, we observed a consistent reduction in cell body immunostaining of pyramidal and granule cells in the hippocampus. In contrast, diffuse staining appeared to increase at these time points in the molecular layer of the dentate gyrus (in particular in the distal area) and in the strata radiatum and oriens. Similar observations were made in thalamic and cortical areas, namely a decrease in cell body staining and an increase in the surrounding diffuse immunoreactivity (data not shown). At $72 \mathrm{hr}$ post-KA injection (Fig. $6 \mathrm{C}$ ), differences in immunostaining were increased further between treated and control hippocampi: TIMP-1 immunoreactivity in pyramidal CA1 neurons virtually was undetectable, whereas it was increased dramatically in all layers of the CA3 and dentate gyrus regions. The presence of strongly immunostained glial cells distributed across all hippocampal laminae was another important feature at $72 \mathrm{hr}$ post-KA. By $14 \mathrm{~d}$ post-KA injection (Fig. $6 D$ ), immunostaining in the hippocampus was still high in the dendritic areas and in glial cells located mostly in the stratum radiatum of region CA1 and in the molecular layers of the dentate gyrus. Microscopic observations at higher magnification (Fig. 7) revealed that TIMP-1 immunoreactivity was distributed homogeneously in the cell bodies of neurons in the strata pyramidale (Fig. $7 A, B$ ) and granulosum (data not shown). In all cases, $8 \mathrm{hr}$ after KA injection, immunostaining in the cell bodies was confined mostly to the perisomatic area and was increased as diffuse immunostaining in the dendritic areas (Fig. 7C,D). At $72 \mathrm{hr}$ post-KA treatment, TIMP-1 immunoreactivity in the CA1 region (Fig. $7 E, F$ ) was strong in cells that appeared to be, by size, morphology, and spatial distribution, mostly astrocytes. These were found primarily in vulnerable structures such as the hippocampus, the entorhinal cortex, and the amygdala and displayed a strong immunoreactivity in the nuclear compartment and also in the processes. Moreover, glial cells located within the corpus callosum were stained more darkly than in control brains.

\section{Delayed neuronal death in the CA1 region after systemic KA injections}

Incipient signs of degeneration in pyramidal neurons of CA1 were detected first by Nissl staining at $24 \mathrm{hr}$ post-KA. At $48 \mathrm{hr}$, degeneration was obvious in this layer (data not shown). At $72 \mathrm{hr}$ post-KA treatment, there was strong evidence for CA1 pyramidal neuron demise, as revealed by Nissl staining (Fig. 7G,H). In keeping with previously reported results (Schowb et al., 1980; Ben-Ari et al., 1981), neuronal degeneration in the hippocampus after KA systemic injections was found mainly in the CA1 stratum pyramidale. Only occasionally did we find overt signs of degeneration in the boundary of CA3 with CA2-CA1 subfields. In any case, degeneration in region CA3 was never detected before $72 \mathrm{hr}$ post-KA treatment. As previously shown (Ben-Ari et al., 1980), the CA3 area is most vulnerable 
CTL
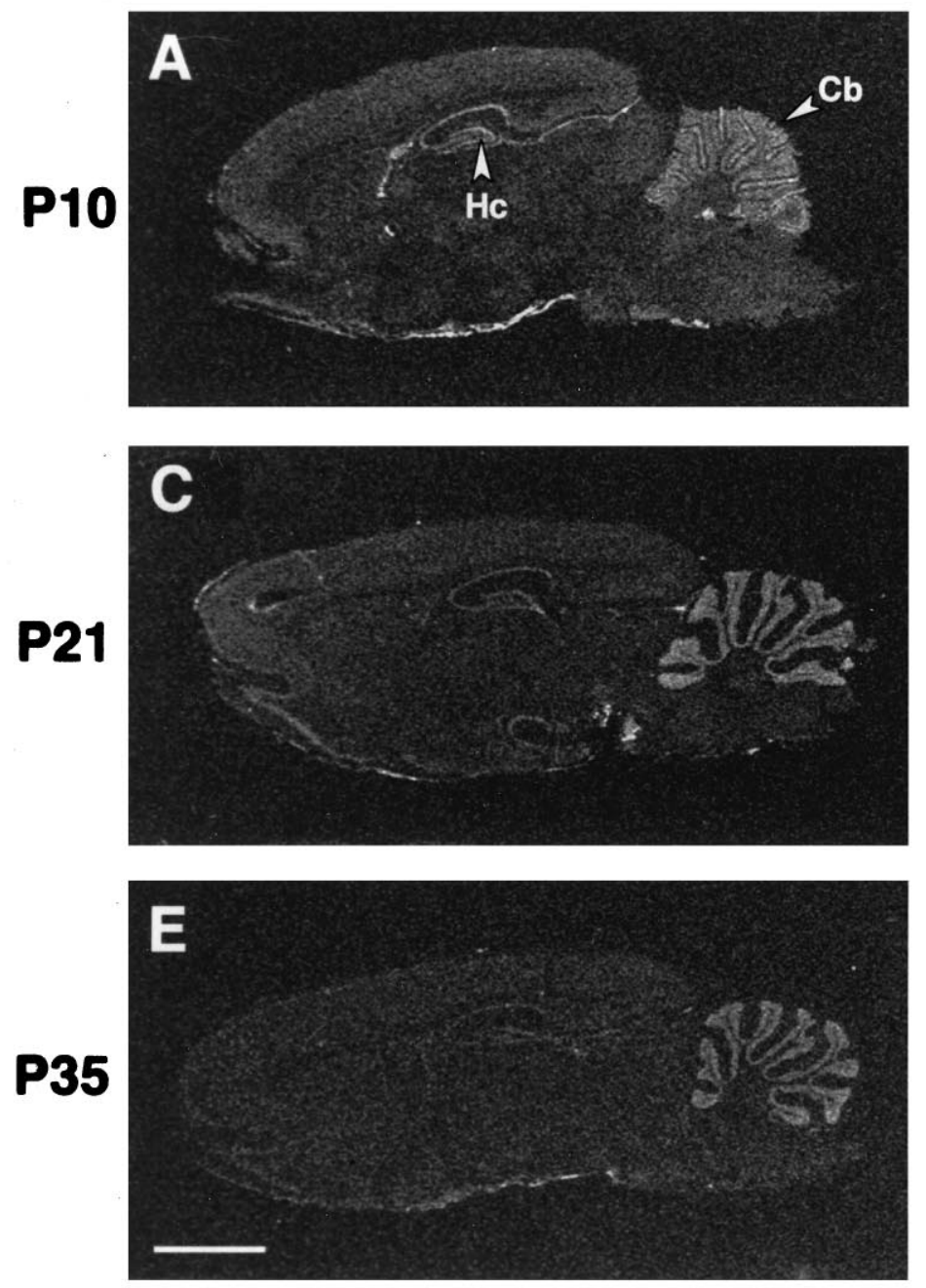

KA
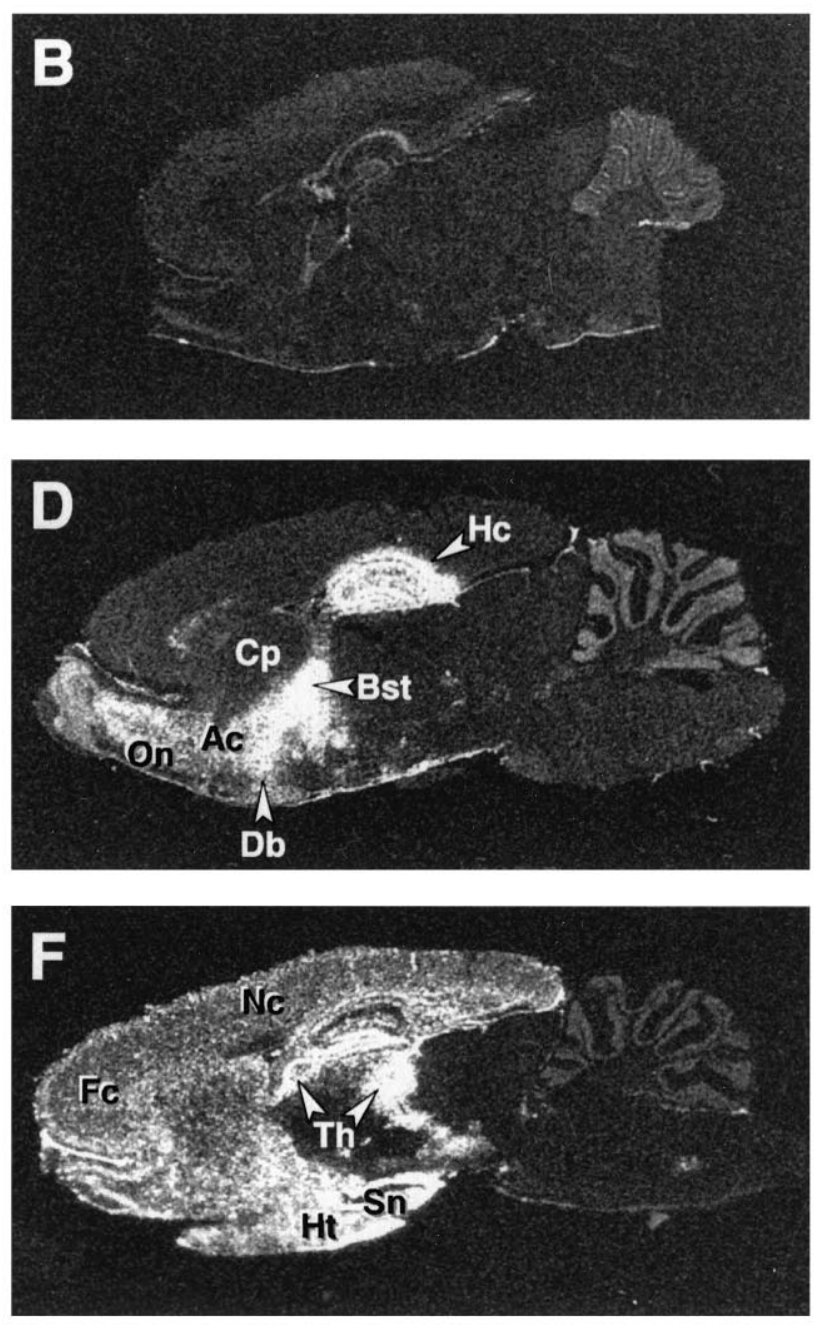

Figure 3. Seizure-induced TIMP-1 mRNA increases are regulated developmentally. Autoradiographs of sagittal brain sections show in situ hybridization to an antisense ${ }^{35}$ S-TIMP-1 cRNA probe at different postnatal ages $(P)$ in control $(C T L)$ and KA-treated $(K A)$ animals. Note in the left column the age-dependent decrease in hybridization in the hippocampus $(H c)$. In the right column seizures do not induce TIMP-1 mRNA in $P 10$ animals $(B)$. At $P 21$ $(D)$, seizures dramatically increase TIMP-1 mRNA in selected structures of the forebrain, including the hippocampus, the bed stria terminalis $(B s t)$, the nucleus accumbens $(A c)$, the diagonal band $(D b)$, and the olfactory nuclei $(O n)$. At $P 35(F)$, seizures induce the expression of TIMP-1 mRNA in nearly all forebrain structures, including the caudate putamen $(C p)$, the neocortex $(N c)$, the hypothalamic nuclei $(H t)$, the substantia nigra $(S n)$, the thalamic nuclei $(\mathrm{Th})$, and the areas of projection of the latter, such as the frontal cortex $(\mathrm{Fc})$. Seizures do not change hybridization in the cerebellum $(\mathrm{Cb})$. Scale bar, $3 \mathrm{~mm}$.

after intra-amygdaloid injections of KA. Other regions that showed signs of neurodegeneration (data not shown) after systemic KA administration include the amygdaloid nuclei, the entorhinal cortex, and the dorsal thalamus, in agreement with Schowb et al. (1980) and with Ben-Ari et al. (1981).

\section{DISCUSSION}

Our results show that KA-induced seizures dramatically upregulate in a region-, time-, and age-dependent manner the mRNA of TIMP-1 in both neurons and astrocytes. We provide evidence that seizure-dependent induction of TIMP-1 mRNA in vivo is independent of de novo protein synthesis, indicating that after seizures TIMP-1 is induced as an IEG. Finally, sustained immunoreactivity of TIMP-1 in vulnerable brain structures such as the hippocampus suggests that it may be involved in tissue repair and/or cell survival after seizures in the mammalian CNS.

\section{TIMP-1 mRNA expression is upregulated differentially in adult and young rats after seizures}

In situ hybridization histochemistry reveals that basal levels of TIMP-1 mRNA are very low in the normal neonatal and adult rat brain, in agreement with previous Northern blot data (Nedivi et al., 1993; Okada et al., 1994). We further have established a developmental downregulation of TIMP-1 mRNA expression in all hippocampal neuronal layers, with the lowest levels found in the adult brain. Developmental changes in TIMP-1 gene expression may be associated with the plastic remodeling of neural tissue during maturation of the brain circuitry, as has been proposed for ECM protease inhibitors (Monard, 1988).

Low basal expression of TIMP-1 mRNA in the normal brain contrasted with its rapid and dramatic induction in the dentate gyrus after KA treatment. The subsequent propagation to other hippocam- 

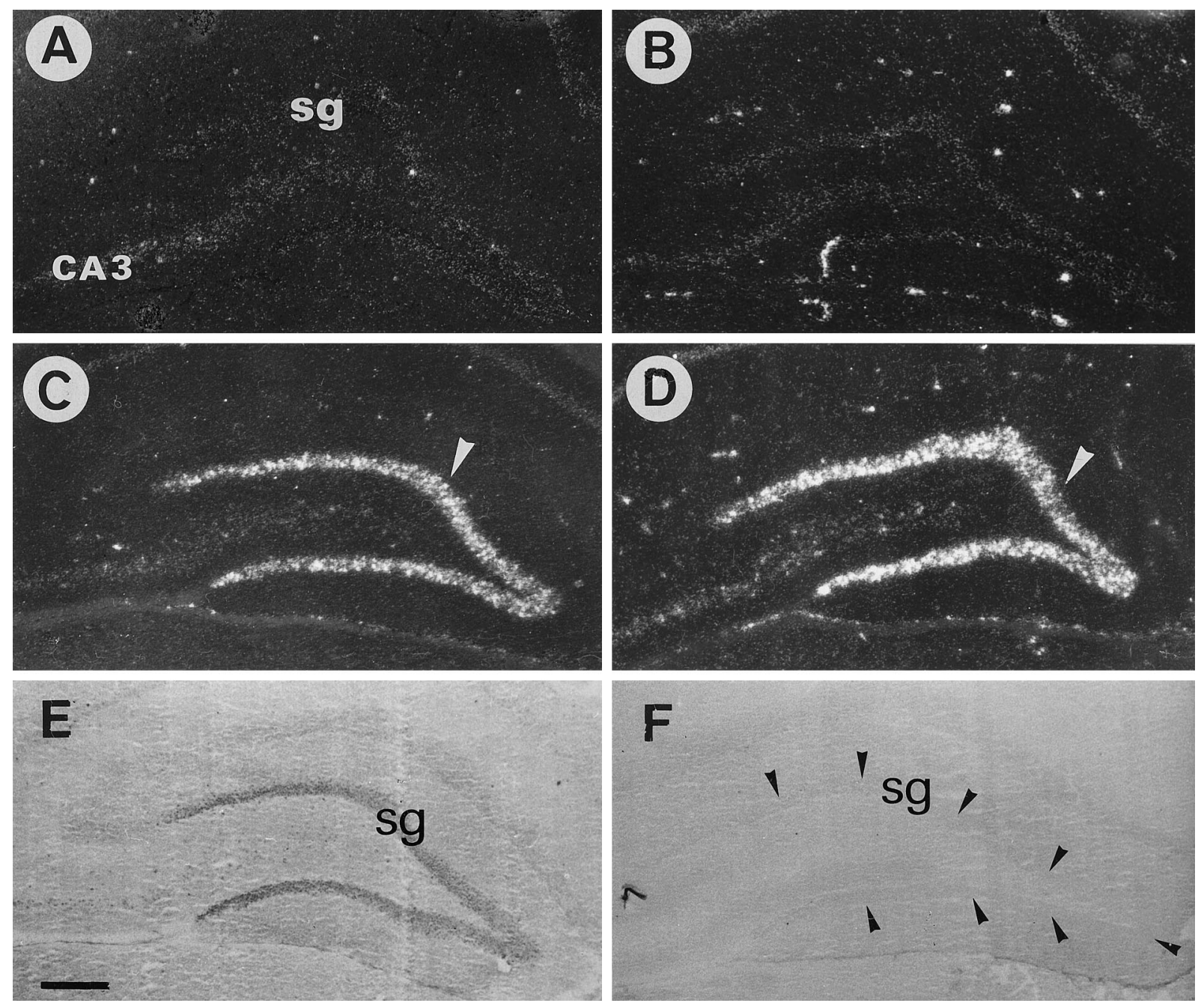

Figure 4. Seizures increase TIMP-1 mRNA expression in the presence of cycloheximide. Dark-field emulsion photomicrographs of coronal brain sections of the medial hippocampus show in situ hybridization to an antisense ${ }^{35}$ S-labeled TIMP-1 cRNA probe $2 \mathrm{hr}$ after treatments with saline $(A)$, saline plus cycloheximide $(B)$, KA $(C)$, and KA plus cycloheximide $(D) . E, F$, Bright-field photomicrographs show immunoreactivity to a Fos-specific antibody in the stratum granulosum $(s g)$ of the dentate gyrus $2 \mathrm{hr}$ after treatment with KA $(E)$ or KA plus cycloheximide $(F)$. Note that, whereas cycloheximide blocked the KA-induced expression of Fos in the stratum granulosum $(F$, black arrowheads), it did not block $(D$, white arrowhead $)$ the KA-mediated induction of TIMP-1 mRNA $(C$, white arrowhead). Fos immunoreactivity in saline and cycloheximide-treated animals was indistinguishable from KA plus cycloheximide (results not shown). Scale bar, $200 \mu \mathrm{m}$.

pal, cortical, and subcortical areas was closely related to the electrographic and metabolic activation of limbic structures after systemic KA injections (Ben-Ari et al., 1981). Interestingly, although TIMP-1 mRNA expression globally decreased at 2 or $3 \mathrm{~d}$ after KA treatment, it remained elevated in areas where degeneration occurred, as confirmed by Nissl staining and in agreement with the well established pattern of pathology produced by systemic KA administration (Schowb et al., 1980; Ben-Ari et al., 1981). These data indirectly suggest that TIMP-1 may be involved in processes of tissue repair and/or cell survival in the injured CNS.

The blockade of KA-mediated TIMP-1 mRNA induction in adult rats by the anticonvulsant drug diazepam indicates that the transcriptional regulation of TIMP-1 expression is activitydependent and not the result of nonspecific effects of KA. Nonetheless, evidence that neuronal activity per se may not be sufficient to trigger TIMP-1 expression is provided by the absence of TIMP-1 induction in 10-d-old animals, despite intense seizure activity manifested by tonicoclonic seizures. Full limbic seizures and emerging signs of pathology in response to KA are not present in rats until the third postnatal week (Nitecka et al., 1984; Tremblay et al., 1984), at which time TIMP-1 mRNA first was seen abundantly induced in the hippocampus and areas of projection. By $35 \mathrm{~d}$ postnatal, when both seizures and pathology are indistinguishable from those of adult rats, TIMP-1 expression extended to all limbic and limbic-related structures. The close parallel between developmental changes in seizures and neuronal vulnerability on one hand and the increased TIMP-1 expression on the other further supports the idea that TIMP-1 is associated with seizureinduced neuropathology. The necessity of a mature limbic system and/or the appropriate signal transduction pathways at a given age may account for differences in the developmental regulation of TIMP-1 after seizures. Because similar developmental patterns of mRNA induction have been documented for c-fos (Schreiber et al., 1992) and brain-derived neurotrophic factor (BDNF) (Dugich-Djordjevic et al., 1992), it is possible 


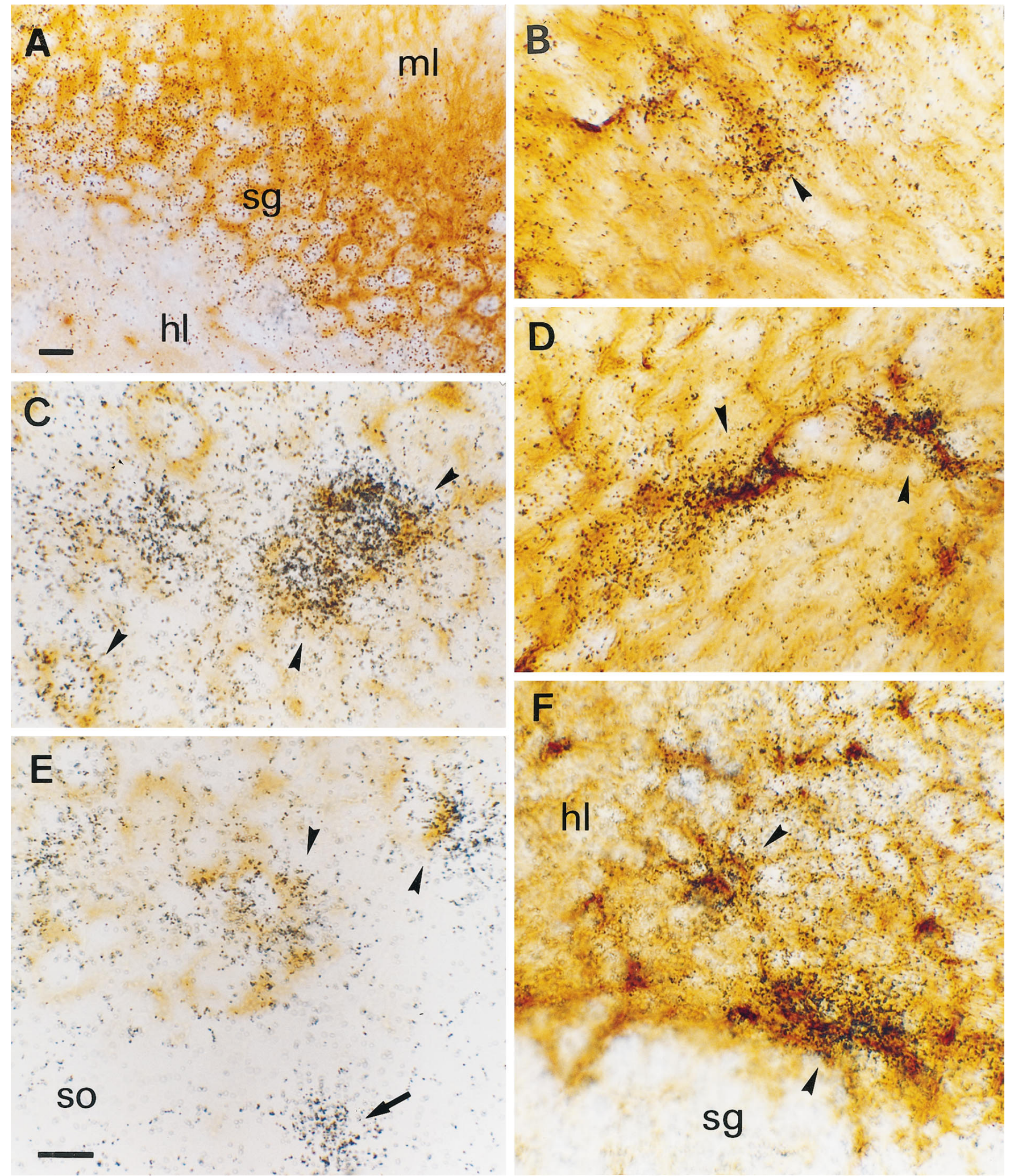

Figure 5. Seizure-induced TIMP-1 mRNA colocalizes with neurons and astrocytes in the adult rat brain. Bright-field photomicrographs show combined in situ hybridization with ${ }^{35}$ S-labeled TIMP-1 cRNA probe and immunohistochemistry with neuronal (MAP-5)-specific and astroglial (GFAP)-specific antibodies. Left column shows MAP-5-positive cells (likely neurons) expressing TIMP-1 mRNA (black silver grains) at 1.5 hr post-KA treatment within the stratum granulosum $(s g)$ of the dentate gyrus $(A)$, at $8 \mathrm{hr}$ in the piriform cortex $(C)$, and at $16 \mathrm{hr}$ in the stratum pyramidale of CA3 $(E)$. $C, E$, Arrowheads mark TIMP-1 labeling over MAP-5-positive cells. E, Arrow marks labeling over a MAP-5-negative cell (likely to be an astrocyte) in the stratum oriens (so) of region CA3. Right column shows GFAP-positive cells (black arrowheads) expressing TIMP-1 mRNA in the stratum radiatum of the hippocampus at $8(B)$ and $16 \mathrm{hr}(D)$ and in the hilus $(h l)$ at $16 \mathrm{hr}(F)$ post-KA treatment. The density of emulsion grains in astrocytes is clearly higher at $16 \mathrm{hr}$ than at $8 \mathrm{hr}$ post-KA treatment. Scale bars, $10 \mu \mathrm{m}$. Scale bar in $E$ is shared with $B-D$ and $F$. 

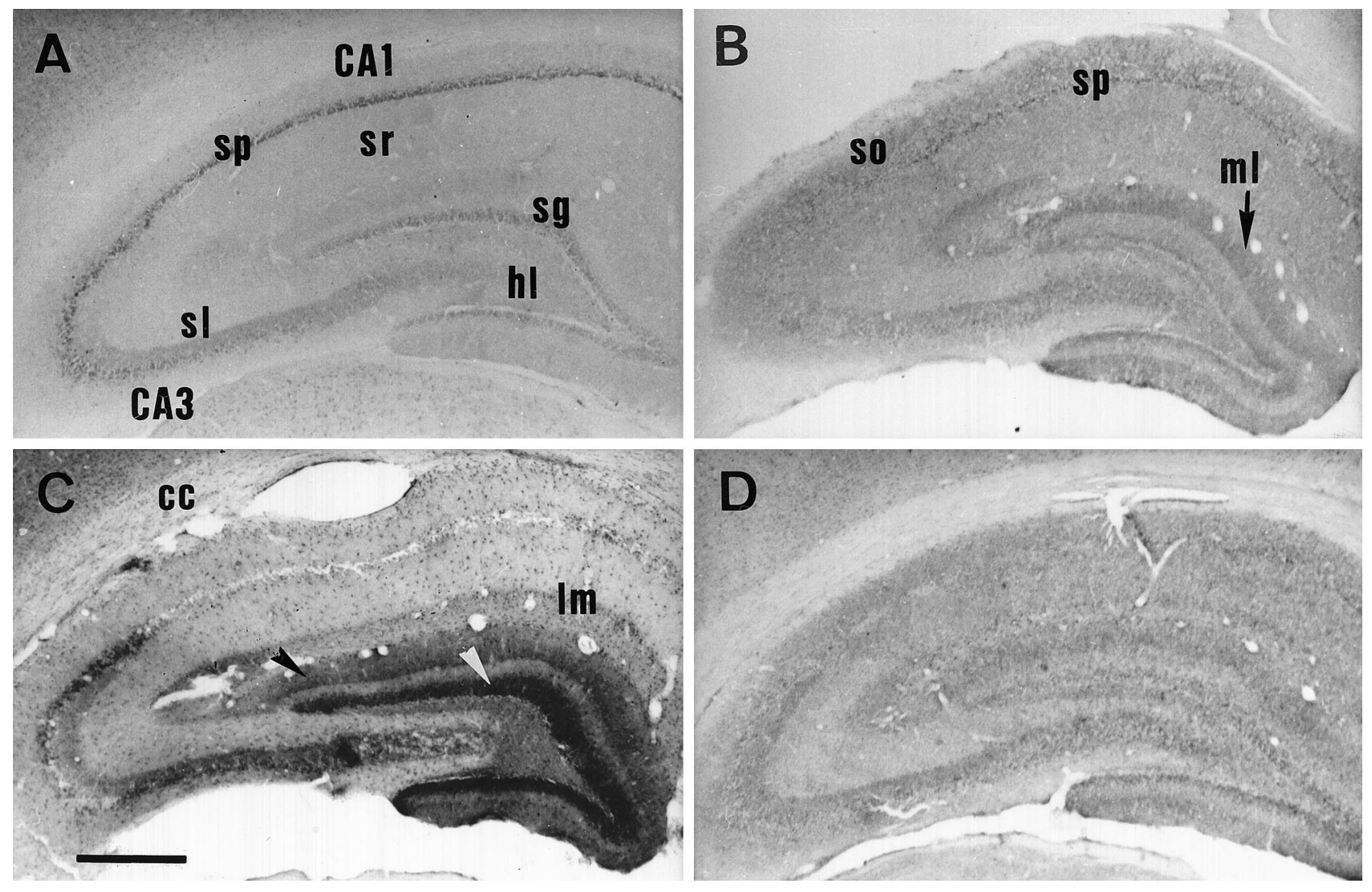

Figure 6. Seizures increase TIMP-1 immunoreactivity in selective hippocampal regions. Bright-field photomicrographs show immunoreactivity to a TIMP-1-specific antibody in coronal brain sections from a control animal $(A)$ and from KA-treated animals at $8(B)$ and $72 \mathrm{hr}(C)$ and at $14 \mathrm{~d}(D)$ post-KA treatment. Note the decrease in immunoreactivity at $8 \mathrm{hr}$ post-KA injection in the strata pyramidale $(s p)$ and granulosum $(s g)$, whereas there is an increase in the stratum radiatum $(s r)$, in the stratum oriens $(s o)$, and in the molecular layer $(m l)$ of the dentate gyrus. At 72 hr post-KA, TIMP-1 immunostaining is increased dramatically in different areas of the dentate gyrus, in particular in the stratum granulosum (white arrowhead) and also in the molecular layer (black arrowhead) and the hilus $(h l)$. Immunostaining at $72 \mathrm{hr}$ also is increased highly in the pyramidal cell layer and in the stratum lucidum $(s l)$ of region $C A 3$ and in the stratum lacunosum moleculare $(\mathrm{lm})$, and immunostaining is reduced in the $C A 1$ pyramidal cell layer. Note also the presence of scattered immunostained cells across all hippocampal areas and in the corpus callosum $(c c)$. At $14 \mathrm{~d}$ post-KA treatment, immunostaining is still elevated in the entire hippocampus outside the main cell body layers. Scale bar, $500 \mu \mathrm{m}$.

that these genes and TIMP-1 share similar stimulus-transcription coupling mechanisms in the brain under intense neuronal activity.

\section{The early TIMP-1 mRNA induction in neurons is independent of de novo protein synthesis}

The TIMP-1 gene also shares with c-fos (Morgan and Curran, 1991) and BDNF (Hughes et al., 1993; Lauterborn et al., 1996) the property of being transcribed as an IEG. Indeed, cycloheximide did not block the KA-mediated induction of TIMP-1 mRNA but did block the induction of Fos protein, indicating that protein synthesis was successfully inhibited, as previously demonstrated in vivo (Jonec and Wasterlain, 1979; Goto et al., 1990; Papas et al., 1992). This raises the possibility that activity-dependent TIMP-1 expression is under the control of consitutively expressed transcription factors that are post-translationally activated. One potential candidate is the protein STAT3 (Signal Transducer and Activator of Transcription 3) that translocates to the nucleus on phosphorylation (see Schindler and Darnell, 1995) and binds to the STAT binding site of the rat TIMP-1 promoter, a major regulatory element in TIMP-1 gene expression (Bugno et al., 1995). Although it is not known whether STAT3 is phosphorylated and activated after seizures, a recent report (Rajan et al., 1995) documents the activation of STAT proteins after axotomy in vivo, suggesting a role for this class of transcription factors in neuronal injury. As an inhibitor of protease activity, an early TIMP-1 expression agrees with the necessity for neurons to develop protective strategies shortly after stress stimuli. Interestingly, the TIMP-1 promoter region also contains an AP-1 binding site (Edwards et al., 1992; Bugno et al., 1995) and may bind AP-1 proteins like Fos or Jun, both induced after seizures (Morgan and Curran, 1991). This site could account for delayed expression of TIMP-1 in both neurons and glial cells, which, in contrast, may depend on novel protein synthesis. Previous in vitro work showing that cycloheximide abrogates serum-mediated TIMP-1 mRNA induction in cultured fibroblasts (Edwards et al., 1985) supports the contention of an alternative mechanism of transcriptional regulation for TIMP-1 in the CNS.

\section{Seizures alter the neuronal distribution and levels of TIMP-1 immunoreactivity}

Ubiquitous TIMP-1 immunoreactivity was detected in neurons across the entire control rat brain. This constitutive expression may exert constant control over the activity of MMPs under physiological conditions.

The upregulation of TIMP-1 mRNA after seizures was followed by generalized increases in TIMP-1 immunoreactivity in most brain structures studied. However, theses increases were delayed 

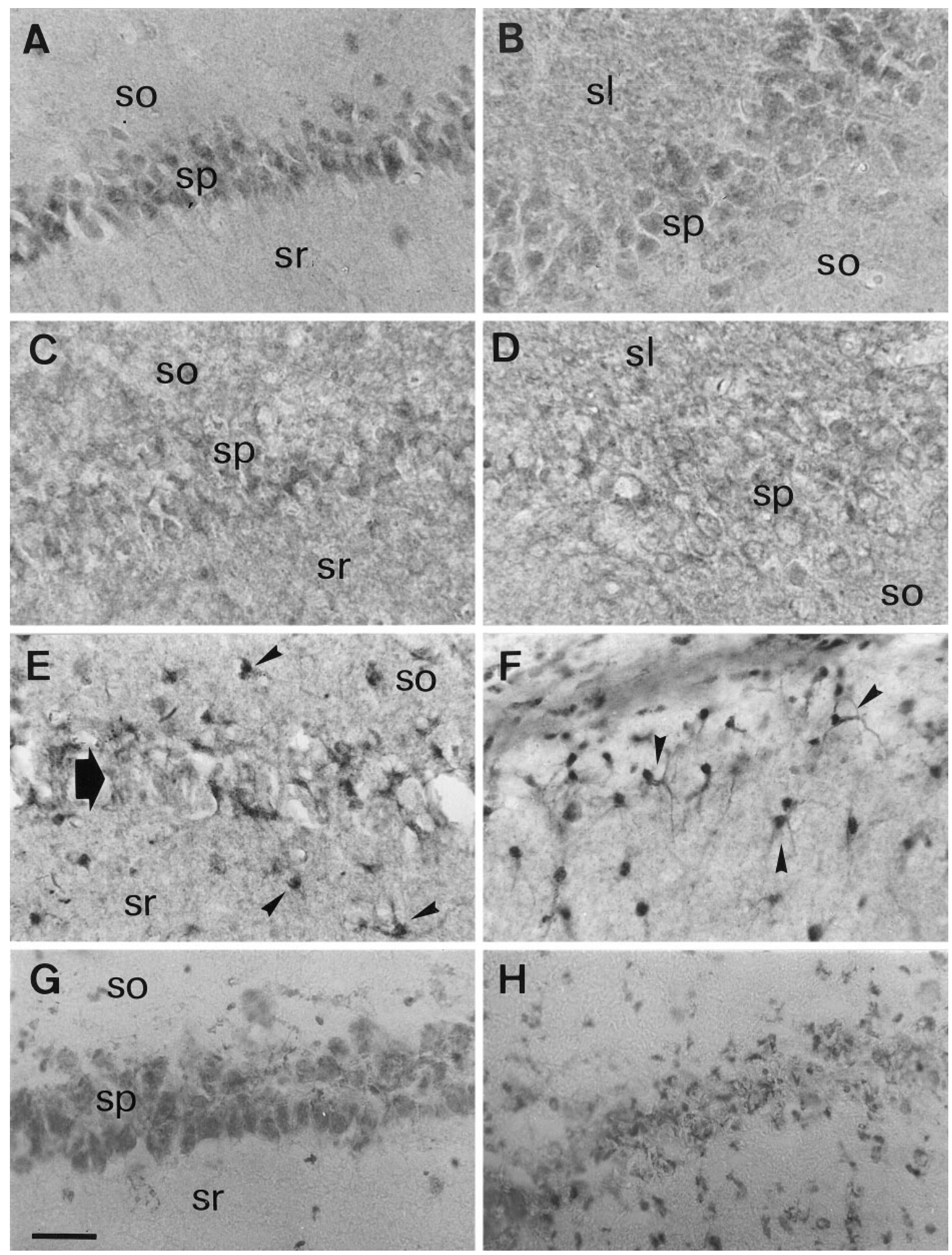

Figure 7. TIMP-1 immunoreactivity increases in the neuronal perisomatic and dendritic areas and in glial cells after seizures. Bright-field photomicrographs show immunoreactivity to a TIMP-1-specific antibody in hippocampal coronal sections of region CA1 $(A, C, E, F)$ and region CA3 $(B, D)$ and Nissl staining $(G, H)$ in the CA1 subfield. $A, B$, TIMP-1 immunoreactivity is distributed homogeneously in pyramidal neurons of CA1 and CA3 of control animals, respectively. At $8 \mathrm{hr}$ post-KA treatment $(C, D)$, immunostaining is increased in the dendritic area; within the cell body it is confined mainly to the perisomatic region. There is no evidence for TIMP-1 expression by glial cells at this time point. At $72 \mathrm{hr}(E, F)$ strong immunostaining is exhibited by glial cells (arrowheads) located outside and within the CA1 cell body layer (large arrow in $E$ ). Remaining neurons in the CA1 cell layer contribute poorly to TIMP-1 immunostaining. $F$, Shown is the stratum oriens of the CA1 region at $72 \mathrm{hr}$ post-KA, presenting darkly stained cells with astrocyte morphology (arrowheads). $G, H$, Shown are Nissl stainings in region CA1 of a control and a KA-treated animal, respectively, $72 \mathrm{hr}$ after KA treatment. Loss of the typical Nissl staining, the shrinkage of neuronal cell bodies, a complete disorganization of the neuronal layer, and the glial reaction are demonstrative of tissue damage. $s l$, Stratum lucidum of region CA3; so, stratum oriens; $s p$, stratum pyramidale; $s r$, stratum radiatum. Scale bar, $50 \mu \mathrm{m}$. 
somewhat after the induction of the mRNA. Indeed, dramatic and rapid induction of TIMP-1 mRNA in the dentate granule cells (90 min after KA) translated into increased immunoreactivity at $8 \mathrm{hr}$ post-KA. At later time points ( $72 \mathrm{hr}$ post-KA) immunoreactivity was elevated in the granule cells, when mRNA levels had returned to control values. Similar discrepancies between mRNA and protein expression after seizures have been reported previously for other proteins such as BDNF (Wetmore et al., 1994; Nawa et al., 1995). In similar experimental paradigms, proteases of the ECM such as tPA (Qian et al., 1993; Tsirka et al., 1995) and MMP3 (Reeben et al., 1996) are induced. The activity of other MMPs also is induced after brain traumatic lesions (Rosenberg, 1995) and focal cerebral ischemia (Rosenberg et al., 1996). The increased expression of TIMP-1, a potent inhibitor of MMP activity, in different neural cells in the stressed brain may be part of a compensatory homeostatic cell response to preserve the integrity of the ECM, challenged by an increase in proteolytic activity. Accordingly, we observed in the hippocampus an increased TIMP-1 immunoreactivity at $8-16 \mathrm{hr}$ post-KA in the perisomatic compartment and in dendritic areas of pyramidal and granule cells. This strongly suggests a translocation of the protein via secretory pathways, in agreement with the secreted nature of TIMP-1 (Murphy et al., 1977; Cawston et al., 1981).

At $72 \mathrm{hr}$ after treatment, TIMP-1 immunoreactivity appears dramatically increased not only in dendro-axonic fields of the hippocampus but also within the granule cell bodies, suggesting differential regulation of TIMP-1 synthesis, stability, transport, and secretion across time. The delayed accumulation of TIMP-1 in these neurons may result from a decreased secretion at a time when astrocytes may contribute significantly to the extracellular TIMP-1 pool, as suggested by their increased immunoreactivity at $72 \mathrm{hr}$ post-KA. At this time point, in the degenerating CA1 area, the sustained TIMP-1 mRNA expression was not correlated with increased immunoreactivity in neurons of this subfield. This apparent paradox may result from an altered capacity to proceed with translation of TIMP-1 or from an increased proteolysis of this protein. Alternatively, glial cells infiltrating the CA1 neuronal layer may contribute to the maintenance of elevated TIMP-1 mRNA levels. Our results demonstrate a good correlation between the absence of TIMP-1 protein in the vulnerable CA1 neurons and the presence of TIMP-1 in resistant granule cells. In brain excitotoxic seizures a local alteration of the MMP/TIMP ratio in favor of proteolytic activity could contribute to the pathological outcome, as suggested in other pathologies (Apodaca et al., 1990; Stetler-Stevenson, 1990; Rosenberg et al., 1992; Shingu et al., 1993; Giraudon et al., 1995; Mohanam et al., 1995). Further biochemical and anatomical studies addressing alterations of the MMP/TIMP ratio will be necessary to elucidate their implication in neuronal plasticity and neuropathology in the seizing brain.

\section{Delayed increase of TIMP-1 in astrocytes of lesioned areas}

The expression of TIMP-1, first in neurons and, as revealed by double-labeling experiments, subsequently also in astrocytes, suggests that TIMP-1 transcriptional regulation in the seizing brain may be cell- and stimulus-dependent. Although neuronal hyperactivity may trigger early TIMP-1 upregulation in neurons, other factors, set in motion by seizures, could influence its expression in both neurons and glial cells at later time points. Among these factors proinflammatory cytokines (i.e., IL- $1 \beta$, TNF- $\alpha$ ) and bFGF, known to be induced by seizures (Minami et al., 1990; Bugra et al., 1994; Gall et al., 1994; de Bock et al., 1996) and supposedly involved in tissue repair after lesions, are efficient modulators of the expression of TIMP-1 in non-neural cells (Edwards et al., 1987; Chua and Chua, 1990; Okada et al., 1990; So et al., 1992; Shingu et al., 1993; Dayer and Burger, 1994). In addition to its most widely recognized function as inhibitor of MMPs, TIMP-1 also exhibits trophic activity (Docherty et al., 1985; Gasson et al., 1985). Experimental evidence indicates that trophic factors can modulate their expressions mutually in the CNS (Yoshida and Gage, 1991; Rivera et al., 1994; Ferhat et al., 1997). In keeping with this notion and considering the complex cellular and temporal expression of TIMP-1 after seizures, it is possible that TIMP-1 contributes to the cascade of trophic interactions among neural cells. It is noteworthy that TIMP-1 immunoreactivity was induced strongly at $72 \mathrm{hr}$ and still elevated at $14 \mathrm{~d}$ in cells morphologically identified as astrocytes. These were observed mainly in vulnerable structures such as the hippocampus, the amygdala, or the entorhinal cortex. Astrocytes synthesize ECM components such as neural cell adhesion molecules (Le Gal La Salle et al., 1992; Niquet et al., 1993), fibronectin (Niquet et al., 1994), or tenascin-C (Niquet et al., 1995) in response to seizures and demonstrate increased MMP activity when stimulated with proinflammatory cytokines (Gottschall and Yu, 1995). Taken together, these data suggest that the contribution of astrocytes to brain tissue remodeling after seizures (Represa et al., 1995) may be, at least in part, based on their capacity to produce essential components of the ECM as well as to regulate its turnover via the modulation of MMPs/TIMPs ratio. The idea of TIMP-1 participating in tissue remodeling after seizures is reinforced by the fact that increased immunoreactivity still was observed in the dendritic areas and in the glial cells of the hippocampus as late as 2 weeks after KA treatment.

In summary, we have described early changes in TIMP-1 mRNA expression and protein localization, along with the differential modulation of these changes across time in neurons and astrocytes. This raises the interesting possibility that TIMP-1 plays a role in coupling early cellular events triggered by environmental stimuli with the intracellular and extracellular regulation of longlasting changes. Additionally, our results support the contention that TIMP-1 influences tissue remodeling and/or neuronal survival after seizures.

\section{REFERENCES}

Apodaca G, Rutka JT, Bouhana K, Berens ME, Giblin JR, Rosenblum ML, McKerrow JH, Banda MJ (1990) Expression of metalloproteinases and metalloproteinase inhibitors by fetal astrocytes and glioma cells. Cancer Res 50:2322-2329.

Apte SS, Mattei M-G, Olsen BR (1994) Cloning of the cDNA encoding human tissue inhibitor of metalloproteinases-3 (TIMP-3) and mapping of the TIMP-3 gene to chromosome 22. Genomics 19:86-90.

Ben-Ari Y, Tremblay E, Ottersen OP (1980) Injections of kainic acid into the amygdaloid complex of the rat: an electrographic, clinical, and histological study in relation to the pathology of epilepsy. Neuroscience 5:515-528.

Ben-Ari Y, Tremblay E, Riche D, Ghilini G, Naquet R (1981) Electrographic, clinical, and pathological alterations following systemic administration of kainic acid, bicuculline, or pentetrazole: metabolic mapping using the deoxyglucose method with special reference to the pathology of epilepsy. Neuroscience 6:1361-1391.

Bertaux B, Hornebeck W, Eisen AZ, Dubertret L (1991) Growth stimulation of human keratinocytes by tissue inhibitor of metalloproteinases. J Invest Dermatol 97:679-685.

Bugno M, Graeve L, Gatsios P, Koj A, Heinrich PC, Travis J, Kordula T (1995) Identification of the interleukin-6/oncostatin $M$ response element in the rat tissue inhibitor of metalloproteinases-1 (TIMP-1) promoter. Nucleic Acids Res 23:5041-5047.

Bugra K, Pollard H, Charton G, Moreau J, Ben-Ari Y, Khrestchatisky M 
(1994) aFGF, bFGF, and flg mRNAs show distinct patterns of induction in the hippocampus following kainate-induced seizures. Eur J Neurosci 6:58-66.

Cawston T, Galloway W, Mercer E, Murphy G, Reynolds J (1981) Purification of rabbit bone inhibitor of collagenase. Biochem J 195:159-165.

Chen Z-L, Yoshida S, Kato K, Momota Y, Suzuki J, Tanaka T, Ito J, Nishino H, Aimoto S, Kiyama H, Shiosaka S (1995) Expression and activity-dependent changes of a novel limbic serine protease gene in the hippocampus. J Neurosci 15:5088-5097.

Chua CC, Chua BHL (1990) Tumor necrosis factor- $\alpha$ induces mRNA for collagenase and TIMP in human skin fibroblasts. Connect Tissue Res 25:161-170.

Dayer J-M, Burger D (1994) Interleukin-1, tumor necrosis factor and their specific inhibitors. Eur Cytokine Netw 5:563-571.

de Bock F, Dornand J, Rondouin G (1996) Release of TNF $\alpha$ in the rat hippocampus following epileptic seizures and excitotoxic neuronal damage. NeuroReport 7:1125-1129.

Docherty AJP, Lyons A, Smith BJ, Wright EM, Stephens PE, Harris TJR, Murphy G, Reynolds JJ (1985) Sequence of human tissue inhibitor of metalloproteinases and its identity to erythroid-potentiating activity. Nature 318:66-69.

Dugich-Djordjevic MM, Tocco G, Willoughby DA, Najm I, Pasinetti G, Thompson RF, Baudry M, Lapchak PA, Hefti F (1992) BDNF mRNA expression in the developing rat brain following kainic acid-induced seizure activity. Neuron 8:1127-1138.

Edwards DR, Parfett CL, Denhardt DT (1985) Transcriptional regulation of two serum-induced RNAs in mouse fibroblasts: equivalence of one species to B2 repetitive elements. Mol Cell Biol 5:3280-3288.

Edwards DR, Murphy G, Reynolds JJ, Whitham SE, Docherty JP, Angel P, Heath JK (1987) Transforming growth factor beta modulates the expression of collagenase and metalloproteinase inhibitor. EMBO J 6:1899-1904.

Edwards DR, Rocheleau H, Sharma R, Wills A, Cowie A, Hassell J, Heath JK (1992) Involvement of AP1 and PEA3 binding sites in the regulation of murine tissue inhibitor of metalloproteinases-1 (TIMP-1) transcription. Biochim Biophys Acta 1171:41-55.

Emonard H, Grimaud J (1990) Matrix metalloproteinases. A review. Cell Mol Biol 36:131-153.

Ferhat L, Represa A, Zouaoui-Aggoun D, Ferhat W, Ben-Ari Y, Khrestchatisky M (1997) FGF-2 induces nerve growth factor expression in cultured rat hippocampal neurons. Eur J Neurosci, in press.

Frey U, Muller M, Kuhl D (1996) A different form of long-lasting potentiation revealed in tissue plasminogen activator mutant mice. J Neurosci 16:2057-2063.

Gall CM, Berschauer R, Isackson PJ (1994) Basic fibroblast growth factor mRNA is increased in forebrain neurons and glia following recurrent limbic seizures. Mol Brain Res 21:190-205.

Gasson JC, Golde DW, Kaufman SE, Westbrook CA, Hewick RM, Kaufman RJ, Wong GG, Temple PA, Leary AC, Brown EL, Orr EC, Clark SC (1985) Molecular characterization and expression of the gene encoding human erythroid-potentiating activity. Nature 315:768-771.

Giraudon P, Thomasset N, Bernard A, Verrier B, Belin MF (1995) Induction of MMP9 (92 kDA gelatinase) activity and expression of tissue inhibitor of metalloproteinases-2 mRNA (TIMP-2) in primitive neuroectodermal cells infected with retrovirus HTLV-1. Eur J Neurosci 7:841-848.

Goto K, Ishige A, Sekiguchi K, Iizuka S, Sugimoto A, Yuzurihara M, Aburada M, Hosoya E, Kogure K (1990) Effects of cycloheximide on delayed neuronal death in rat hippocampus. Brain Res 534:105-116.

Gottschall PE, Yu X (1995) Cytokines regulate gelatinase A and B (matrix metalloproteinase 2 and 9) activity in cultured rat astrocytes. J Neurochem 64:1513-1520.

Hayakawa T, Yamashita K, Tanzawa K, Uchijima E, Iwata K (1992) Growth-promoting activity of tissue inhibitor of metalloproteinases-1 (TIMP-1) for a wide range of cells. A possible new growth factor in serum. FEBS Lett 298:29-32.

Hodgson J (1995) Remodeling MMPIs. Biotechnology 13:554-557.

Hughes P, Beilharz E, Gluckman P, Dragunow M (1993) Brain-derived neurotrophic factor is induced as an immediate early gene following $N$-methyl-D-aspartate receptor activation. Neuroscience 57:319-328.

Jonec V, Wasterlain GC (1979) Effects of inhibitors of protein synthesis on the development of kindled seizures in rats. Exp Neurol 66:524-532.

Khokha R, Waterhouse P, Yagel S, Lala PK, Overall CM, Norton G, Denhardt DT (1989) Antisense RNA-induced reduction in murine
TIMP levels confers oncogenicity on Swiss $3 \mathrm{~T} 3$ cells. Science 243:947-950.

Lauterborn JO, Rivera S, Stinis CT, Hayes VY, Isackson PJ, Gall CM (1996) Differential effects of protein synthesis inhibition on the activitydependent expression of BDNF transcripts: evidence for immediate early gene responses from specific promoters. J Neurosci 16:7428-7436.

Leco JK, Khokha R, Pavloff N, Hawkes SP, Edwards DR (1994) Tissue inhibitor of metalloproteinases-3 (TIMP-3) is an extracellular matrixassociated protein with a distinctive pattern of expression in mouse cells and tissues. J Biol Chem 269:9352-9360.

Lee KS, Frank S, Vanderklish P, Arai A, Lynch G (1991) Inhibition of proteolysis protects hippocampal neurons from ischemia. Proc Natl Acad Sci USA 88:7233-7237.

Le Gal La Salle G, Rougon G, Valin A (1992) The embryonic form of neural cell surface molecule (E-NCAM) in the rat hippocampus and its reexpression on glial cells following kainic acid-induced status epilepticus. J Neurosci 12:872-882.

Lynch G, Baudry M (1984) The biochemistry of memory: a new and specific hypothesis. Science 224:1057-1063.

Minami M, Kuraishi Y, Yamaguchi T, Nakai S, Hirai Y, Satoh M (1990) Convulsants induce interleukin-1 beta messenger RNA in rat brain. Biochem Biophys Res Commun 171:832-837.

Mohanam S, Wang SW, Rayford A, Yamamoto M, Sawaya R, Nakajima M, Liotta LA, Nicolson GL, Stetler-Stevenson WG, Rao JS (1995) Expression of tissue inhibitors of metalloproteinases: negative regulators of human glioblastoma invasion in vivo. Clin Exp Metastasis 13:57-62.

Monard D (1988) Cell-derived proteases and protease inhibitors as regulators of neurite outgrowth. Trends Neurosci 11:541-544.

Morgan JI, Curran T (1991) Stimulus-transcription coupling in the nervous system: involvement of the inducible proto-oncogenes fos and jun. Annu Rev Neurosci 14:421-451.

Murphy G, Cartwright EC, Sellers A, Reynolds JJ (1977) The detection and characterisation of collagenase inhibitors from rabbit tissues in culture. Biochim Biophys Acta 483:493-498.

Murphy G, Reynolds JJ, Werb Z (1985) Biosynthesis of tissue inhibitor of metalloproteinases by human fibroblasts in culture. J Biol Chem 260:3079-3083.

Murphy G, Houbrechts A, Cockett M, Williamson RA, O'Shea M, Docherty AJP (1991) The N-terminal domain of tissue inhibitor of metalloproteinases retains metalloproteinase inhibitory activity. Biochemistry 30:8097-8102.

Nakagawa T, Kubota T, Kabuto M, Sato K, Kawano H, Hayakawa T, Okada Y (1994) Production of matrix metalloproteinases and tissue inhibitor of metalloproteinases-1 by human brain tumors. J Neurosurg 81:69-77.

Nawa H, Carnahan J, Gall C (1995) BDNF protein measured by a novel enzyme immunoassay in normal brain and after seizure: partial disagreement with mRNA levels. Eur J Neurosci 7:1527-1535.

Nedivi E, Hevroni D, Naot D, Israeli D, Citri Y (1993) Numerous candidate plasticity-related genes revealed by differential cDNA cloning. Nature 363:718-722.

Niquet J, Jorquera I, Ben-Ari Y, Represa A (1993) NCAM immunoreactivity on mossy fibers and reactive astrocytes in the hippocampus of epileptic rats. Brain Res 626:106-116.

Niquet J, Jorquera I, Ben-Ari Y, Represa A (1994) Proliferative astrocytes may express fibronectin-like protein in the hippocampus of epileptic rats. Neurosci Lett 180:13-16.

Niquet J, Jorquera I, Faissner A, Ben-Ari Y, Represa A (1995) Gliosis and axonal sprouting in the hippocampus of epileptic rats are associated with an increase of tenascin-C immunoreactivity. J Neurocytol 24:611-624.

Nitecka L, Tremblay E, Charton G, Bouillot JP, Berger ML, Ben-Ari Y (1984) Maturation of kainic acid seizure-brain damage syndrome in the rat. II. Histopathological sequelae. Neuroscience 13:1073-1094.

Okada A, Garnier J-M, Vicaire S, Basset P (1994) Cloning of the cDNA encoding rat tissue inhibitor of metalloproteinase 1 (TIMP-1), amino acid comparison with other TIMPs, and gene expression in rat tissues. Gene 147:301-302.

Okada Y, Tsuchiya H, Shimizu H, Tomita K, Nakanishi I, Sato H, Seiki M, Yamashita K, Hayakawa T (1990) Induction and stimulation of $92 \mathrm{kDa}$ gelatinase/type IV collagenase production in osteosarcoma and fibrosarcoma cell lines by tumor necrosis factor $\alpha$. Biochem Biophys Res Commun 171:610-617.

Papas S, Crépel V, Hasboun D, Jorquera I, Chinestra P, Ben-Ari Y 
(1992) Cycloheximide reduces the effects of anoxic insult in vivo and in vitro. Eur J Neurosci 4:758-765.

Pennacchio LA, Lehesjoki A-E, Stone NE, Willour VL, Virtaneva K, Miao J, D'Amato E, Ramirez L, Faham M, Koskiniemi M, Warrington JA, Norio R, de la Chapelle A, Cox DR, Myers RM (1996) Mutations in the gene encoding cystatin B in progressive myoclonus epilepsy (EPM1). Science 271:1731-1734.

Qian Z, Gilbert ME, Colicos MA, Kandel ER, Kuhl D (1993) Tissueplasminogen activator is induced as an immediate early gene during seizure, kindling, and long-term potentiation. Nature 361:453-457.

Rajan P, Stewart CL, Fink SJ (1995) LIF-mediated activation of STAT proteins after neuronal injury in vivo. NeuroReport 6:2240-2244.

Reeben M, Abratova J, Riekkinen P, Saarma M (1996) Role of a calcium-activated metalloprotease stromelysin-1 (transin) in the brain damage during epileptic seizures. J Neurochem 66:S56.

Represa A, Niquet J, Pollard H, Ben-Ari Y (1995) Cell death, gliosis, synaptic remodeling in the hippocampus of epileptic rats. J Neurobiol 26:413-425.

Rivera S, Gold SJ, Gall CM (1994) Interleukin-1 $\beta$ increases basic fibroblast growth factor mRNA expression in adult rat brain and organotypic hippocampal cultures. Mol Brain Res 27:12-26.

Rosenberg GA (1995) Matrix metalloproteinases in brain injury. J Neurotrauma 12:833-842.

Rosenberg GA, Kornfeld M, Estrada E, Kelley RO, Liotta LA, StetlerStevenson WG (1992) TIMP-2 reduces proteolytic opening of bloodbrain barrier by type IV collagenase. Brain Res 576:203-207.

Rosenberg GA, Navratil L, Barone F, Feurstein G (1996) Proteolytic cascade enzymes increase in focal cerebral ischemia in rat. J Cereb Blood Flow Metab 16:360-366.

Schindler C, Darnell JE (1995) Transcriptional responses to polypeptide ligands: the JAK-STAT pathway. Annu Rev Biochem 64:621-651.

Schowb J, Fuller T, Price J, Olney J (1980) Widespread patterns of neuronal damage following systemic or intracerebral injections of kainic acid: a histological study. Neuroscience 5:991-1014.

Schreiber SS, Tocco G, Najm I, Finch CE, Johnson SA, Baudry M (1992)
Absence of c-fos induction in neonatal rat brain after seizures. Neurosci Lett 136:31-35.

Shingu M, Nagai Y, Isayama T, Naono T, Nobunaga M, Nagai Y (1993) The effects of cytokines on metalloproteinase inhibitors (TIMP) and collagenase production by human chondrocytes and TIMP production by synovial cells and endothelial cells. Clin Exp Immunol 94:145-149.

Siman R, Noszek JC, Kegerise C (1989) Calpain I activation is specifically related to excitatory amino acid induction of hippocampal damage. J Neurosci 9:1579-1590.

Skup D, Windass JD, Sor F, George H, Williams BR, Fukuhara H, De Maeyer-Guignard J, De Maeyer E (1982) Molecular cloning of partial cDNA copies of two distinct mouse IFN-beta mRNAs. Nucleic Acids Res 10:3069-3084.

So T, Ito A, Sato T, Mori Y, Hirakawa S (1992) Tumor necrosis factor- $\alpha$ stimulates the biosynthesis of matrix metalloproteinases and plasminogen activator in cultured human chorionic cells. Biol Reprod 46:772-778.

Stetler-Stevenson WG (1990) Type IV collagenases in tumor invasion and metastasis. Cancer Metastasis Rev 9:289-303.

Stetler-Stevenson WG, Krutzsch HC, Liotta LA (1989) Tissue inhibitor of metalloproteinase (TIMP-2). A new member of the metalloproteinase inhibitor family. J Biol Chem 264:17374-17378.

Tremblay E, Nitecka L, Berger ML, Ben-Ari Y (1984) Maturation of kainic acid seizure-brain damage syndrome in the rat. I. Clinical, electrographic, and metabolic observations. Neuroscience 13:1051-1072.

Tsirka SE, Gualandris A, Amaral DG, Strickland S (1995) Excitotoxininduced neuronal degeneration and seizure are mediated by tissue plasminogen activator. Nature 377:340-344.

Wetmore C, Olson L, Bean JB (1994) Regulation of brain-derived neurotrophic factor (BDNF) expression and release from hippocampal neurons is mediated by non-NMDA type glutamate receptors. J Neurosci 14:1688-1700.

Yoshida K, Gage F (1991) Fibroblast growth factors stimulate nerve growth factor synthesis and secretion by astrocytes. Brain Res 538: $118-126$. 